\title{
AUGMENTED ANASTOMOTIC URETHROPLASTY FOR LONG SEGMENT BULBOUS URETHRAL STRICTURES
}

\author{
By
Mohamed Ibrahim Al-Gammal, Abdullah Mohamed Abdullah, Abul- Fotouh Abd El-Maguid Abul-Fotouh and Gamal Ibrahim Selmy \\ Department of Urology, Al-Azhar Faculty of Medicine, Cairo, Egypt \\ Corresponding author: Mohamed Ibrahim Al-Gammal;
}

Mobile: 0100319556; E-mail: gemykarter2020@ gmail.com

\begin{abstract}
Background: During urethroplasty, if the stricture contains a 2 to $4 \mathrm{~cm}$ region that is particularly narrow and/or fibrotic, anastomotic repair is not ideal, so that portion may be excised with subsequent anastomosis of the ventral aspect of the urethra to shorten, widen and optimize the urethral wall onto which an onlay graft is to be placed. This procedure is termed augmented anastomotic urethroplasty

Objectives: Evaluation of the outcome of augmented anastomotic urethroplasty with dorsal onlay for long segment bulbar urethral stricture.

Patients and Methods: A prospective clinical trial was carried out during the period from March 2017 to September 2019 of 55 patients underwent dorsal onlay augmented anastomosis using buccal mucosa graft for long segment bulbar urethral strictures. All patients underwent pre-operative medical history taking and physical examination, sono-urethrography and voiding cystourethrogram. Patients were followed-up and reassessed at 3 and 6 months post-operatively. Follow-up urethrography was performed at 6 months. The primary outcome was the procedure success rate defined by the successful voiding function. Stricture recurrence was defined the presence of intractable voiding symptoms or the need for any urethral interventions. The data were analyzed using the appropriate statistical tests.

Results: During the study period, 55 patients completed the follow-up protocol and included in the study. The mean age was $41.93 \pm 10.70$ years. The mean intra-operative stricture length was $3.39 \pm 0.59 \mathrm{~cm}$. Buccal mucosal graft was used in all cases. Mean graft length was $4.15 \pm 0.62 \mathrm{~cm}$. At 6 months follow up, 51 patients had no evidence of stricture recurrence and required no further intervention with an overall success rate of 92.7\%. Stricture recurrence occurred in 4 patients (7.3\%). No donor site major complications were detected. The urethroplasty complication rate was $20.0 \%$, and all were minor. No effect of urethroplasty on erectile function in adult sexually active patients. No penile shortening or chordee.
\end{abstract}

Conclusions: Dorsal onlay augmented anastomosis was a useful technique for long bulbar strictures. High stricture-free rates and complications are few and minor. Although longer follow up was needed.

Key words: Reconstructive surgery, Stricture, Urethral reconstruction, bulbar.

\section{INTRODUCTION}

Anterior urethral stricture is a common disorder, especially among elderly, with annual incidence ranges from 200 to 1200 patients per 100,000 individuals; and negative impact on the health-related quality of life and costs (Reyad et al., 2018).

Moreover, untreated urethral strictures may lead to acute retention and prostatitis 
in more than $50 \%$ of the patients (Mundy and Andrich, 2011). Bulbar urethra is the most commonly affected site by strictures and accounts for approximately $45 \%$ of the cases (Palminteri et al., 2013). Although bulbar urethral strictures may be a consequence of instrumentation or infection, especially sexually transmitted diseases, the majority of the cases are idiopathic or congenital in origin (Mundy and Andrich, 2011), in which iatrogenic causes are responsible for $50 \%$ of these cases (Reyad et al., 2018).

Various several surgical techniques have been described for bulbar urethral stricture. The choice of the optimal treatment options largely relays on the length of stricture, the density of the spongiofibrosis, and surgeon's experience (Hampson et al., 2014). In patients with short incomplete stricture $(<2 \mathrm{~cm})$, stricture excision and primary anastomosis are the most commonly used strategies with favorable long-term outcomes (Reyad et al., 2018).

The published literature shows controversies with regard to the treatment of choice for longer strictures. Although some reports suggested that bulbar anastomotic urethroplasty can be used in selected patients with proximal bulbar urethral strictures up to $5 \mathrm{~cm}$, some investigators show that substitution urethroplasty, using a buccal mucosal graft (BMG), is the standard for the management of bulbar urethral strictures $>2 \mathrm{~cm}$ with limited fibrosis, in order to avoid the high risk of risk penile chordee or shortening associated with excision and re-anastomosis (Joshi et al., 2016).
The study was conducted to evaluate the outcome of dorsal onlay buccal mucosal graft augmentation of long segment bulbous urethral strictures.

\section{PATIENTS AND METHODS}

This prospective clinical trial was carried out during the period from March 2017 to September 2019 at the Urology Department; Al-Hussein and Sayed Galal, Al-Azhar University Hospitals; Cairo; Egypt. The research ethics committee of our institution approved the study protocol and all participants provided informed written consents before inclusion.

The study included male patients with long-segment bulbous urethral strictures $(2-4 \mathrm{~cm})$ that were not amenable for end to end anastomotic urethroplasty. Patients with associated co-morbidities precluding the use of buccal mucosal graft were excluded from the study.

All patients with stricture urethra were evaluated for possible study participation, by:

1. Complete medical history taking: including International prostatic symptom score (IPSS) and International index of erectile function (IIEF-5) questionnaire (in adult sexually active men).

2. Physical examination.

3. Urine analysis.

4. Uroflowmetery.

5. Urethrography.

6. Abdomiopelvic ultrasonography

7. Sonourethrography (SUG).

All patients with bulbar urethral stricture $(2-4 \mathrm{~cm})$ in which two ends are 
sufficiently elastic to allow them to be brought together end to end without tension but not sufficiently elastic to be able to get an overlapping anastomosis without tension were operated using the technique of an augmented anastomosis with a buccal mucosa graft in a dorsal onlay fashion. In this technique the dense urethral segment is excised, followed by anastomosis of the ventral urethral wall. Reconstruction is completed by dorsal placement of a buccal mucosa graft into the remaining urethrotomy defect.

During the early post-operative period, all patients were observed for donor site morbidity and urethroplasty wound complications. Peri-urethrogram was performed 3 weeks post-operatively and urethral catheter was removed if no contrast leakage. Immediately after catheter removal, the patients were observed for voiding trial and continence. Patients with successful voiding were scheduled for regular follow-up and reevaluated at the $3^{\text {rd }}$ and $6^{\text {th }}$ months postoperative follow-up time points by:

1. Complete medical history taking: including voiding trial and continence.

2. Physical examination including genital and oral examination.

3. Uroflowmetery; and Abdomino-pelvic ultrasonography. Urethrography and IIEF-5 score (in adult sexually active men) measurement were done at the $6^{\text {th }}$ month follow-up time point.

The primary outcome was the urinary function as evaluated by the continence status, I-PSS, Qmax, post-void residual urine volume and urethrogram. Procedure failure (stricture recurrence) is defined as the need for re-do surgery or additional intervention. The secondary outcomes included operative time, peri-operative complications, hospitalization time, catheter duration, penile deformity, erectile function and donor site morbidity.

The collected data were organized, tabulated and statistically analyzed using statistical package for social science (SPSS) version 25 software (SPSS Inc, USA). The included sample size was sufficient to estimate the outcome of dorsal onlay augmented anastomotic urethroplasty in study subjects with $95 \%$ confidence level (CL) and confidence interval (CI) of width $\pm 5 \%$. Descriptive statistics were performed for all study variables with a normality test for all quantitative variables. Quantitative variables were expressed as mean \pm standard deviation (SD), median, range and interquartile range (IQR). Qualitative variables were expressed as number $(\%)$. Pre- and post-operative value of different variables were compared using the independent sample t-test or MannWhitney U-test for numerical data and Chi-Square or Fisher Exact test for categorical data. Correlations between two variables have been calculated using Pearson's or Spearman's correlation coefficient. Differences have been considered significant when probability (p) value $<0.05$. 


\section{RESULTS}

Out of 58 patients who underwent an augmented anastomotic urethroplasty with a dorsal onlay fashion using a buccal mucosa graft at our institution, during the study period, 55 completed the study protocol and included in data analysis.

The mean age of 55 study subjects was $41.93 \pm 10.70$ years (range: 15.00 to 63.00 years). Eleven (20.0\%) patients had a history of previous surgeries for stricture urethra. The main presenting symptoms was obstructive lower urinary tract symptoms (LUTS), in the form of weak stream of urine and straining during micturition in $38(69.1 \%)$ and fixed suprapubic catheter in 17 (30.9\%) patients. Out of 55, 52 patients were sexually active; from them 30 patients had some degree of erectile dysfunction (ED) as evaluated by IIEF5 questionnaire. The demographic data and historical characteristics of studies patients were summarized in Table (1).

\section{Table (1): Demographics and historical characteristics of studied 55 patients}

\begin{tabular}{|l|c|}
\hline Variables & Data \\
\hline Age, (years) & $41.93 \pm 10.70$ \\
Mean \pm SD & $44.00(15.00$ to 63.00$)$ \\
Median (minimum to maximum) & 48.00 \\
Range & $38(69.1)$ \\
\hline Presenting symptoms, n (\%) & $17(30.9)$ \\
Obstructive LUTS & \\
Fixed S.P. Catheter & $22.22 \pm 3.82$ \\
\hline International prostatic symptom score (IPSS) & 18.00 to 30.00$)$ \\
Mean \pm SD & 5.00 \\
Median (minimum to maximum) & \\
Range & $11.18 \pm 8.18$ \\
IQR & $7(4.00$ to 36.00$)$ \\
\hline Symptoms' duration, (months) & 32.00 \\
Mean \pm SD & 6.00 \\
Median (minimum to maximum) & $11(20.0)$ \\
Range & $6(10.9)$ \\
IQR & $5(9.1)$ \\
\hline Previous treatment of stricture urethra, $\mathrm{n}(\%)$ & $5(9.1)$ \\
Visual internal urethrotomy + Urethral dilation & \\
Once & $43(78.2)$ \\
Twice & $5(9.6)$ \\
Open urethroplasty* & $3(5.8)$ \\
\hline Erectile dysfunction**, n (\%) & $4(7.7)$ \\
No ED & \\
Mild & \\
Moderate & \\
Severe & \\
\hline
\end{tabular}

*IPSS was calculated only in 38 patients with urethral voiding.

**All patients with past history of open urethroplasty had a previous history of visual internal urethrotomy.

***The erectile function was evaluated only in 52 sexually active men. 
Ultrasound measurement of post voiding residual urine (PVR) urine volume and free uroflowmetry was performed in 38 patients with urethral voiding. The PVR urine volume ranged from 80.00 to $180.00 \mathrm{~mL}$ (mean: 116.62 \pm 1.77 ; median: 29.35; range: 100.00 and IQR: $33 \mathrm{~mL}$ ). The uroflowmetry was non-conclusive in 12 patients due to small voided urine volume or inability to void in the uroflowmetry machine. In all, the uroflow curve was plateau with prolonged voiding time and low maximum urinary flow rate (Qmax). The Qmax ranged from 2.40 to 9.00 mL/Sec. (mean: 5.35 \pm 1.77 ; median: 5.45; range: 6.60 and IQR: $3.03 \mathrm{~mL} / \mathrm{Sec}$.).
Thirteen $(23.6 \%)$ of patients had no reported etiology of urethral stricture. In the remaining 52 patients, the main etiologies of urethral stricture were postinflammatory $(\mathrm{n}=18$; "32.7\%"), urethral trauma (n=9; "16.4\%") and iatrogenic urethral injury $(\mathrm{n}=9$; "16.4\%"), Two $(23.7 \%)$ patients had a multifactorial cause of urethral stricture. All included cases had a single bulbar urethral stricture. The mean stricture length as evaluated by cystourethrogram was $3.21 \pm 0.57 \mathrm{~cm}$. The mean stricture length as evaluated by ultrasonography was $3.43 \pm 0.60 \mathrm{~cm}$ Table (2).

Table (2): Urethral stricture characteristics in the studied 55 patients

\begin{tabular}{|l|c|}
\hline Variables & Data \\
\hline Aetiology of urethral stricture, $\mathrm{n}(\%)$ & $13(23.6)$ \\
Idiopathic & $9(16.4)$ \\
Iatrogenic urethral injury & $13(23.6)$ \\
External urethral trauma & $18(32.7)$ \\
Inflammatory cause & $2(3.6)$ \\
Multifactorial cause & $3.21 \pm 0.57$ \\
\hline Stricture length as measured on cystourethrogram, (cm) & $3.00(2.00$ to 4.00$)$ \\
Mean \pm SD & 2.00 \\
Median (min. to max.) & $3.43 \pm 0.60$ \\
Range & $3.50(2.00$ to 4.50$)$ \\
Stricture length as measured by ultrasound, (cm) & 2.50 \\
Mean \pm SD & \\
Median (min. to max.) & $16(29.1)$ \\
Range & $5(9.1)$ \\
\hline Spongiofibrosis as detected by ultrasound, $\mathrm{n}(\%)$ & $7(12.73)$ \\
Mild & \\
Moderate & \\
Severe & \\
\hline
\end{tabular}

A significant relation was observed between the presence of spongiofibrosis and previous VIU and open urethroplasty
(Phi: 0.677 and 0.688 , respectively) $(\mathrm{p}=0.039$; Eta: 0.342), Table (3). 
MOHAMED IBRAHIM AL-GAMMAL et al.,

Table (3): Presence and grades of sopngiofibrosis according to different demographic and historical characteristics, in the studied 55 patients

\begin{tabular}{|c|c|c|c|c|c|c|}
\hline \multirow{3}{*}{ Variables } & \multirow{2}{*}{ No. } & \multicolumn{4}{|c|}{ Spongiofibrosis } & \multirow{2}{*}{$\mathrm{p}$ value } \\
\hline & & No & Mild & Moderate & Severe & \\
\hline & & & & & & \\
\hline Age, years & & & & & & 0538 \\
\hline$\leq 50$ & 44 & $22(50.0)$ & $14(31.8)$ & $3(6.8)$ & $5(11.4)$ & 0.550 \\
\hline$>50$ & 11 & $5(45.5)$ & $2(18.2)$ & $2(18.2)$ & $2(18.2)$ & \\
\hline Etiology of stricture & & & & & & 0349 \\
\hline Idiopathic & 13 & $6(46.2)$ & $3(23.1)$ & $2(15.4)$ & $2(15.4)$ & 0.349 \\
\hline Iatrogenic injury & 9 & $6(66.7)$ & $1(11.1)$ & $1(11.1)$ & $1(11.1)$ & \\
\hline External trauma & 13 & $3(23.1)$ & $8(61.5)$ & $1(7.7)$ & $1(7.7)$ & \\
\hline Inflammatory & 18 & $11(61.1)$ & $4(22.2)$ & $1(5.6)$ & $2(11.1)$ & \\
\hline Multifactorial & 2 & $1(50.0)$ & $0(0.0)$ & $0(0.0)$ & $1(50.0)$ & \\
\hline Duration of symptoms & & & & & & (17) \\
\hline$\leq 12$ months & 42 & $22(52.4)$ & $13(31.0)$ & $4(9.5)$ & $3(7.1)$ & $0.1 / 2$ \\
\hline$>12$ months & 13 & $5(38.5)$ & $3(23.1)$ & $1(7.7)$ & $4(30.8)$ & \\
\hline History of VIU & & & & & & $<0.001$ \\
\hline No & 44 & $25(56.8)$ & $15(34.1)$ & $5(4.5)$ & $2(4.5)$ & $<0.001$ \\
\hline Once & 6 & $2(38.5)$ & $1(34.6)$ & $1(11.5)$ & $2(15.4)$ & \\
\hline Twice & 5 & $0(50.0)$ & $0(0.0)$ & $2(0.0)$ & $3(50.0)$ & \\
\hline History of urethroplasty & & & & & & $<0001$ \\
\hline No & 50 & $27(54.0)$ & $16(32.0)$ & $4(8.0)$ & $3(6.0)$ & -0.001 \\
\hline Yes & 5 & $0(0.0)$ & $0(0.0)$ & $1(20.0)$ & $4(80.0)$ & \\
\hline
\end{tabular}

The mean intra-operative stricture length was $3.39 \pm 0.59 \mathrm{~cm}$. Buccal mucosal graft was used in all cases. The mean graft length was $4.15 \pm 0.62$ and mean graft width was $1.76 \pm 0.25$. The mean overall operative time was $144.45 \pm 24.26$ minutes. Intra-operative blood transfusion was needed in $3(5.5 \%)$ cases. Only one unit of whole blood was transfused in each case. The need for blood transfusion was decided on the basis of brisk intraoperative hemorrhage and hemodynamic instability, i.e. not quickly responding to crystalloid infusion) Table (4). 
Table (4): Intra-operative parameters in the studied 55 patients

\begin{tabular}{|l|c|}
\hline Variables & Data \\
\hline Intra-operative stricture length, (cm) & $3.39 \pm 0.59$ \\
Mean \pm SD & $3.50(2.00$ to 4.50$)$ \\
Median (min. to max.) & 2.50 \\
Range & $3.21 \pm 0.57$ \\
\hline Graft length, (cm) & $4.00(3.00$ to 5.00$)$ \\
Mean \pm SD & 2.00 \\
Median (min. to max.) & \\
Range & $1.76 \pm 0.25$ \\
\hline Graft width, (cm) & $2.00(1.00$ to 2.00$)$ \\
Mean $\pm S D$ & 0.50 \\
Median (min. to max.) & $27(49.1)$ \\
Range & $28(50.9)$ \\
\hline Urethral Catheter size, $\mathrm{n}(\%)$ & $42(76.4)$ \\
16 Fr. & $3(5.5)$ \\
18 Fr. & \\
\hline Use of Redivac drain, $\mathrm{n}(\%)$ & $144.45 \pm 24.26$ \\
\hline Need for blood transfusion, $\mathrm{n}(\%)$ & 90.00 \\
\hline Overall operative time, minute & 40.00 \\
Mean \pm SD & \\
Median (minimum to maximum) & $145.00(90.00$ to 180.00$)$ \\
Range & \\
IQR & \\
\hline
\end{tabular}

At post-operative day one, all patients experienced pain at donor site. It was mild in $39(70.9 \%)$ patients and moderate in 16 $(29.1 \%)$ patients. Forty-six $(83.6 \%)$ patients were pain free and $9(16.4 \%)$ had mild pain after 36 hours. All patients were pain free after 2 weeks. All patients were able to resume oral fluids within 24 hours, soft solid diet by 48 hours and returned to normal diet after 3 to 5 days. There was no infection, bleeding or hematoma at donor site with no salivatory changes.

Eleven (20.0\%) developed an early post-operative complication(s). Eight (14.5\%) patients were complicated by urethroplasty wound infection within one week. All of them were managed conservatively with empirical IV broad spectrum antibiotics and non-steroidal anti-inflammatory drugs (NSAIDs) plus drainage of the wound by opening one stitch from suture line. Six (10.9\%) patients developed post-operative hematoma at wound site that managed conservatively without intervention except in 5 patients, in which the hematoma was accompanied with wound infection, who were managed with antibiotics, NSAIDs and wound drainage. Two $(3.6 \%)$ patients developed epididymo-orchitis that managed with empirical broad-spectrum antibiotics, NSAIDs and scrotal support. All patients were discharged home with urethral catheter with 4 days median duration of hospital stay.

Regarding the peri-catheter urethrogram performed 3 weeks after surgery, no contrast leakage was noted in $50(90.9 \%)$ patients and the urethral catheter was removed after urethrography. In $5(8.1 \%)$ patients, mild contrasted leakage was detected; the catheter was left in place and removed one week later. After urethral catheter removal, all patients micturated well; good urinary stream and continent voiding. No continence problems, donor site morbidity, penile length affection or 
penile chordee were noted during the postoperative follow up periods.

At the end of study, 4 patients showed IPSS above 7, 5 showed Qmax below 15 $\mathrm{mL} / \mathrm{sec}$. And only one patient showed a residual urine volume $>100 \mathrm{cc}$. According to the post-operative IIEF-5 score, 8 (15.4\%) patients had ED. From them, only $2(3.8 \%)$ developed new onset ED; one developed moderate ED with a total score 10 and the other developed sever ED with a total score 5. Twelve cases had essentially low IIEF-5 pre-operatively, 6 of them improved at 6 months follow up. The IPSS, Qmax, PVR urine volume and IIEF5 at different follow-up time points compared with the pre-operative values were summarized in Table (5).

Table (5): The IPSS, Qmax, PVR urine volume and IIEF5 at different follow-up time points compared with the pre-operative values

\begin{tabular}{|c|c|c|c|c|}
\hline Variables & Pre-operative & $\begin{array}{c}\text { Post-operative } \\
\left(3^{\text {rd }} \text { month }\right)\end{array}$ & $\begin{array}{l}\text { Post-operative } \\
\left(6^{\text {th }} \text { month }\right)\end{array}$ & p-value \\
\hline $\begin{array}{l}\text { IPSS } \\
\text { Mean } \pm \text { SD } \\
\text { Median (min. to max.) } \\
\text { Range } \\
\text { IQR }\end{array}$ & $\begin{array}{c}22.21 \pm 3.81 \\
20 .(18.00-30.00) \\
12 \\
5.00\end{array}$ & $\begin{array}{c}0.86 \pm 1.15 \\
0.00(0.00-5.00) \\
5.00 \\
1.5\end{array}$ & $\begin{array}{c}1.13 \pm 2.55 \\
0.00(0.00-15.00) \\
15.00 \\
2.00\end{array}$ & $<0.001^{\text {a) }}$ \\
\hline $\begin{array}{l}\mathrm{Q}_{\max },(\mathrm{mL} / \mathrm{sec} .) \\
\text { Mean } \pm \mathrm{SD} \\
\text { Median (min. to max.) } \\
\text { Range } \\
\text { IQR }\end{array}$ & $\begin{array}{c}5.34 \pm 1.77 \\
5.45(2.4-9) \\
6.60 \\
3.03 \\
\end{array}$ & $\begin{array}{c}25.03 \pm 4.05 \\
24.00(18.00-34.00) \\
16.00 \\
6.25\end{array}$ & $\begin{array}{c}23.76 \pm 5.018 \\
23.00(7.9-35.00) \\
27.00 \\
5.75\end{array}$ & $<0.001^{\text {b) }}$ \\
\hline $\begin{array}{l}\text { PVR urine volume, }(\mathrm{cc}) \\
\text { Mean } \pm \text { SD } \\
\text { Median (min. to max.) } \\
\text { Range } \\
\text { IQR }\end{array}$ & $\begin{array}{c}116.62 \pm 29.34 \\
100.00(80-160) \\
100 \\
33\end{array}$ & $\begin{array}{c}8.00 \pm 14.03 \\
0.00(0.00-60.00) \\
60 \\
18\end{array}$ & $\begin{array}{c}4.38 \pm 14.15 \\
0.00(0.00-60.00) \\
60 \\
10\end{array}$ & $<0.001^{\mathrm{c})}$ \\
\hline $\begin{array}{l}\text { IIEF5 score } \\
\text { Mean } \pm \text { SD } \\
\text { Median (min. to max.) } \\
\text { Range } \\
\text { IQR }\end{array}$ & $\begin{array}{c}19.66 \pm 5.88 \\
22.00(6.00-24.00) \\
18 \\
1.75\end{array}$ & $\begin{array}{l}-- \\
-- \\
-- \\
--\end{array}$ & $\begin{array}{c}20.09 \pm 5.86 \\
22.00(4.00-25.00) \\
21 \\
1.00\end{array}$ & 0.706 \\
\hline
\end{tabular}

Paired comparisons: a) No significant difference between data at 3 and 6 months $(p=0.160)$. b) a significant difference was observed between data at 3 and 6 months $(\mathrm{p}=0.004)$. c) No significant difference between data at 3 and 6 months $(\mathrm{p}=0.445)$. Others $(<0.001)$.

The Ascending and voiding cystourethrography (AVCUG) was performed at post-operative month 6 . It was normal in $51(92.7 \%)$ patients. Four patients showed stricture recurrence; one patient developed stricture at the proximal end of the graft and 3 patients developed stricture at the distal end of the graft. The 51 (92.7\%) patients with normal AVCUG had I-PSS below 7, Qmax above 15 $\mathrm{mL} / \mathrm{sec}$. with no significant PVR urine volume. Those patients were considered to have a successful procedure Figure (1). 


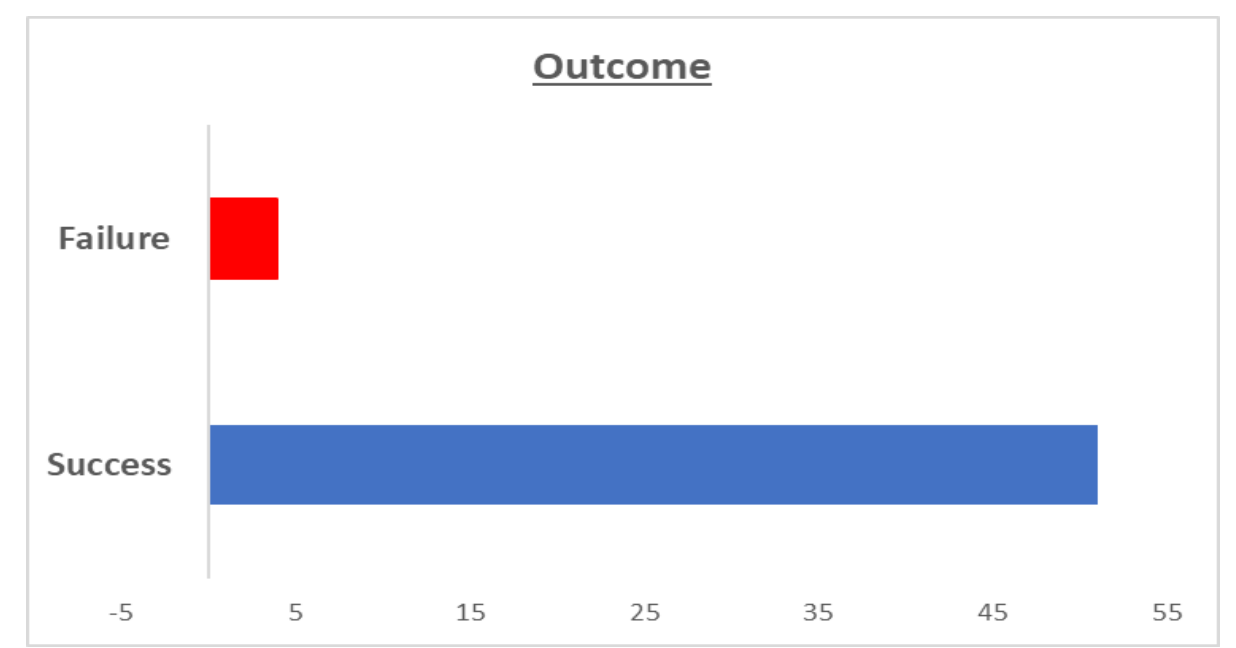

Figure (1): Histogram demonstrating the overall success of the procedure among the studied 55 patients

Regarding the failed cases, one needed a re-do urethroplasty and the other 3 cases had a short segment passable stricture and managed by visual internal urethrotomy (VIU). Those patients passed the peri-

\section{DISCUSSION}

Urethroplasty is well established as the most efficacious treatment for urethral stricture especially those strictures failing endoscopic treatment (Chapman et al., 2017). The surgical management of bulbar urethral stricture has changed dramatically in the last several decades (Akio and Masayuki, 2019).

While there is a consensus in the published literature about the high success rate of stricture excision and primary anastomosis in the management of short bulbar urethral stricture, the primary anastomotic procedure of a longer urethral segment carries the risks of penile shortening or chordee (Reyad et al., 2018).

Augmented anastomotic repair is an urethroplasty technique that incorporates the principles of stricture resection, primary urethral anastomosis, and operative period smoothly without complication and micturated well after urethral catheter removal; However, no data available about the delayed outcome.

substitution urethroplasty. In the present study all strictures were bulbar, single strictures that treated by unilateral buccal mucosal dorsal onlay augmented anastomotic urethroplasty and had at least 6 months follow-up.

At the end of the present study, there was significant improvement in the following parameters: Q max, IPSS, PVR urine volume and IIEF5 score $(\mathrm{P}<0.001)$. The overall success rate of the procedure was $92.7 \%$.

Surgical failure proved radio logically and by SPSS and Qmax in 4 cases. This stricture recurrence was at proximal end of the graft in one patient and distal end in 3 patients.

The success rate in the present study was nearly equal to the results of Hoy et al. (2013), Virasoro et al. (2015) and Kunz et al. (2018), studies. In which the success rate was $90.1 \%, 96.9 \%$ and 
$96.9 \%$, respectively. The success is slightly of lower rate in a study by Kotov (2019) at which operative efficiency index was $(88.2 \%)$ of 17 patients. Similar results reported by Reyad et al. (2018) was $(87.5 \%)$ of 40 patients who underwent dorsal strip urethroplasty. The difference in success rate between various series may be explained by different definitions of success, number of patients in each study, complexity of cases and surgeons' experience in different series.

No intra-operative donor site major complications in our study. At the first postoperative day, all patients experienced pain at donor site that was mild in $70.9 \%$ and moderate in $29.1 \%$. After two weeks, all patients were pain free. There was no infection, bleeding or hematoma at donor site with no salivatory changes. These results were similar to most of previous studies. No major donor site major complications were reported in studies of Virasoro et al. (2015) and (Kunz et al. (2018).

Higher incidence of donor site morbidities was noted in Hoy et al. (2013) study, in which orchalgia developed in $10.4 \%$ and donor site morbidity in $4.3 \%$. In all cases, orchalgia was transient and had resolved without treatment by 6 months. Patients experiencing donor site morbidity presented with paresthesia, tightness, or pain, all of which had resolved without treatment by the 12month follow-up period.

In the present study, $20.0 \%$ developed an early post-operative complication(s) in the form of urethroplasty wound infection, hematoma at wound site and epididymoorchitis. None of patients developed early or late continence problems. Similar results were noted in other studies by Kotov (2019). In other series, post-voiding dribbling developed in $22.7 \%, 41.7 \%$ and $40.4 \%$, and all improved over time without intervention by Hoy et al. (2013), Virasoro et al. (2015) and Kunz et al. (2018) studies. This difference mostly due to difference in stricture length, number of studied patients or strength and variability in handling of bulbo-spongiosus muscle during dissection and closure.

Some patients perceive post micturition dribbling and associated semen sequestration as bothersome. Many patients complaining of urinary incontinence after surgery actually have instead significant post micturition dribbling, as actual stress urinary incontinence is very uncommon after urethral surgery (Shenfeld, 2014).

According to the post-operative IIEF-5 score, $15.4 \%$ patients had ED. From them, $3.8 \%$ developed new onset ED; one developed moderate ED with a total score 10 and the other developed severe ED with a total score 5. Twelve cases had essentially low IIEF-5 pre-operatively and 6 of them improved at 6 months follow up.

At the end of the present study, 8 patients had ED. From them, only 2 developed new onset ED. no significant difference was observed between IIEF5 score pre-operatively and 6 months postoperatively. Kotov (2019) reported that de novo erectile dysfunction was not observed in any of study patients.

Other study also reported the same results that the adverse effect of urethroplasty itself on erectile function is limited, as more patients recover erectile function after urethral reconstruction. 
Trauma might be the main cause of ED (Feng et al., 2013). The same results also were reported in other studies with a conclusion that anterior urethroplasty with or without buccal grafting has a transient adverse effect on erectile function which spontaneously improved within 6-12 months (Fiorello et al., 2019).

None of our patients developed postoperative penile curvature or significant penile shortening as an urethroplasty complication. Reyad et al. (2018) reported 2 cases of penile curvature one with dorsal strip repair and the other with ventral strip repair with insignificant statistical difference between both groups; Penile curvature also was reported in 3 cases (4.2\%) of a study by Kunz et al. (2018).

This variation in incidence of penile shortening and curvature may be due to different stricture sites and mean stricture lengths between different studies.

In the present study, the median hospital stay was 4 days. In most of studies (Hoy et al., 2013; Virasoro et al., 2015; Bugeja et al., 2016; Reyad et al., 2018), the hospital stay period ranged from 24 to 48 hours, with no comment on the impact of hospital stay period on urethroplasty outcome mostly due to very short hospitalization time.

Limitations of our study were, short follow up period, and inability to perform histopathology of excised stricture segment due to financial issues. We recommend longer follow up period and future studies on large number of patients with histopathological examination of the excised stricture segment.

\section{CONCLUSION}

Dorsal onlay augmented anastomosis was a feasible technique for long bulbar strictures. It has a high success rate and its complications were few and minor.

\section{CONFLECT OF INTERREST}

None.

\section{REFERENCES}

1. Abouassaly, R. and Angermeier, K.W., (2007): Augmented anastomotic urethroplasty. The Journal of Urology, 177, 2211-2216.

2. Akio $H$ and Masayuki S., (2019): Substitution Urethroplasty for Bulbar Urethral Strictures, quoted from Textbook of Male Genitourethral Reconstruction pp 191208.

3. Bugeja S, Ivaz S, Frost AV, Andrich DE and Mundy AR., (2016): Non-transecting bulbar urethroplasty using buccal mucosa. African Journal of Urology, 22(1):47-53.

4. Chapman D, Kinnaird A and Rourke K., (2017): Independent Predictors of Stricture Recurrence Following Urethroplasty for Isolated Bulbar Urethral Strictures, The Journal of Urology, 201, 1107-1026.

5. El-Kassaby, A.W., El-Zayat, T.M., Azazy, S. and Osman, T., (2008): One-stage repair of long bulbar urethral strictures using augmented Russell dorsal strip anastomosis: outcome of 234 cases. European Urology, 53: 420-424.

6. Feng C, Xu YM, Barbagli G, Lazzeri M, Tang CY, Fu Q and Sa YL., (2013): The relationship between erectile dysfunction and open urethroplasty: a systematic review and meta-analysis. The Journal of Sexual Medicine, 1; 10(8):2060-8.

7. Fiorello N, Jallous H, Porru D, Marchetti C, Giliberto G, Regina C, Ringressi A, Cebrelli $T$ and Simeone C., (2019): Anterior Urethroplasty for Urethral Stricture and Subsequent Erectile Dysfunction. Correlations and Treatments in the Literature. World J Urol. 27; 16(3): 175-80. 
8. Guralnick, M.L. and Webster, G.D., (2001): The augmented anastomotic urethroplasty: indications and outcome in 29 patients. The Journal of Urology, 165, 14961501.

9. Hampson, L.A., McAninch, J.W. and Breyer, B.N., (2014): Male urethral strictures and their management. Nature Reviews Urology, 11, 43-61

10. Hoy N., Kinnaird A. and Rourke K., (2013): Expanded Use of a dorsal onlay augmented anastomotic urethro $\neg$ plasty with buccal mucosa for long segment bul $\neg$ bar urethral strictures: analysis of outcomes and complications. Urology, 81: 1357-1361.

11. Joshi, P., Kaya, C. and Kulkarni, S., (2016): Approach to bulbar urethral strictures: Which technique and when? Turkish journal of urology, 42: 53-71.

12. Kotov S.V., (2019): Augmented non transecting anastomotic urethroplasty (Kodama's operation), Eur Urol Suppl; 18(1); e2295- 2304.

13. Kunz I, Musch M, Vogel A, Maek M, Roggenbuck U, Krege S and Kroepfl D., (2018): Experience with one-stage repair of urethral strictures using the augmented anastomotic repair technique. Urologia internationalis, 100(4):386-96.
14. Lee, Y.J. and Kim, S.W., (2013): Current management of urethral stricture. Korean Journal of Urology, 54, 561-569.

15. Mundy, A.R. and Andrich, D.E., (2011): Urethral strictures. BJU international 107, 626.

16. Palminteri, E., Berdondini, E., Verze, P., De Nunzio, C., Vitarelli, A. and Carmignani, L., (2013): Contemporary urethral stricture characteristics in the developed world. Urology, 81, 191-197.

17. Reyad, A.M., Mamdouh, A., Rashed, E., Fathi, A., Mahmoud, O. and Hasan, A., (2018): Dorsal versus ventral strip augmented anastomotic bulbar urethroplasty: retrospective study. International Urology and Nephrology, 50: 1257-1261.

18. Shenfeld O., (2014): Complications of urethroplasty. InAdvanced Male Urethral and Genital Reconstructive Surgery, (pp. 305320). Humana Press, New York, NY.

19. Virasoro R, Storme OA, Capiel L, Ghisini DA and Rovegno A., (2015): Buccal mucosa graft augmented anastomotic urethroplasty for the treatment of bulbar urethral strictures. Arch Esp Urol., 1; 68(10):730. 


\section{علاج الضيق الطويل بالجزء البصلي لمجرى البول عن البن البز

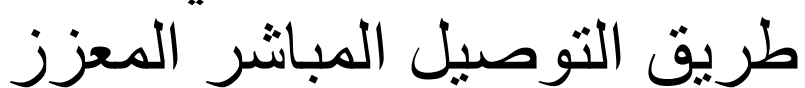

محمد ابراهيم الجمال، عبدالله محمد عبدالله، ابوالفتوح عبدالمجيد ابوالقتوح، جمال

$$
\text { ابر اهيم سلمي }
$$

قسم جراحة المسالك البولية، كلية الطب، جامعة الأزهر، القاهرة، مصر

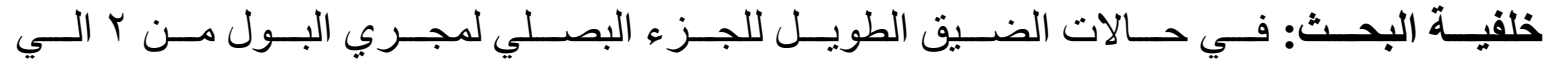

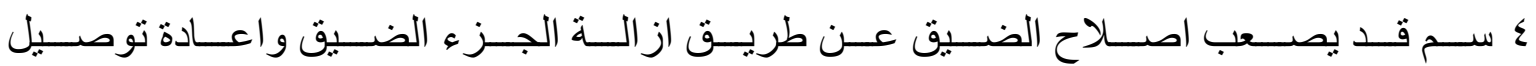

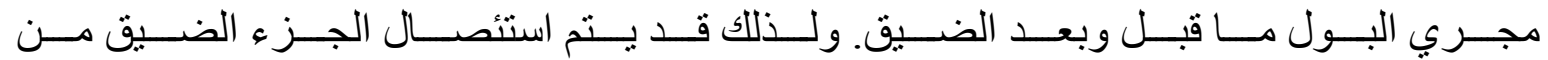

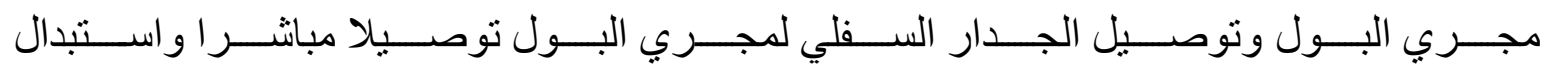
الجدار العلوي لمجري البول باستخدام رقعة مخاطية.

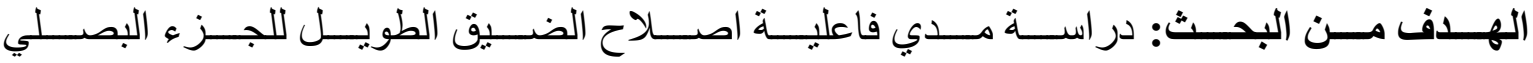

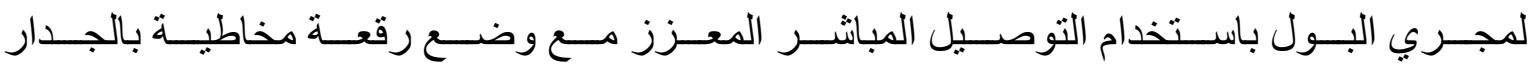
العلوي لمجري البول وتوصيل الجدار السفلي.

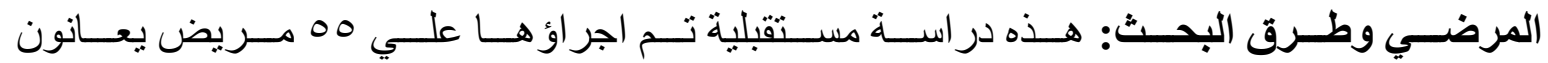

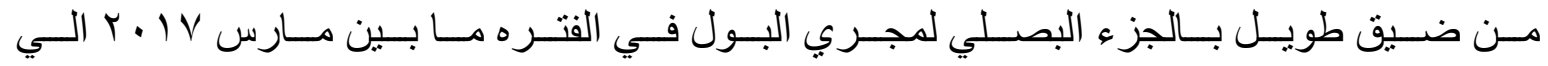

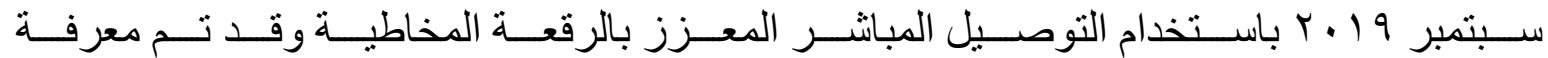

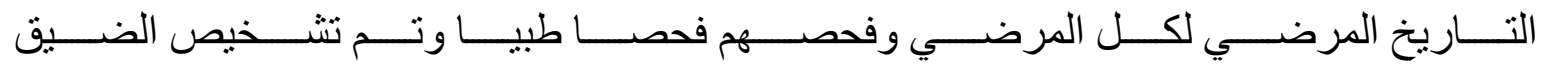

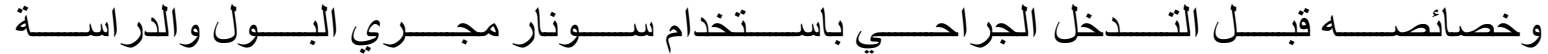

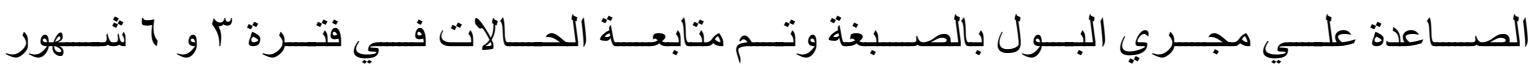

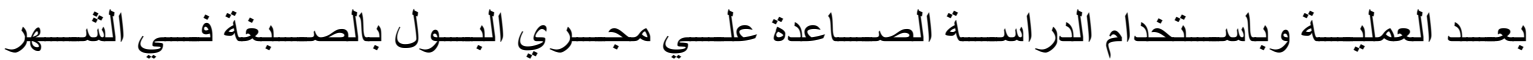

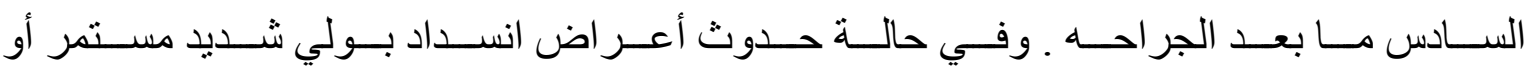

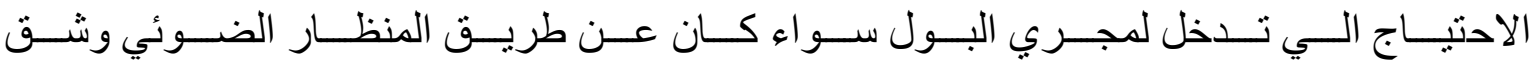

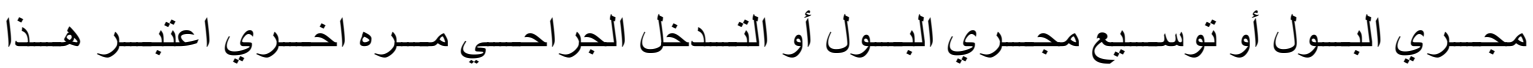
فنشل للاجر اء الجر احي.وتم متابعة حدوث اي مضاعفات ما بعد العمليه.

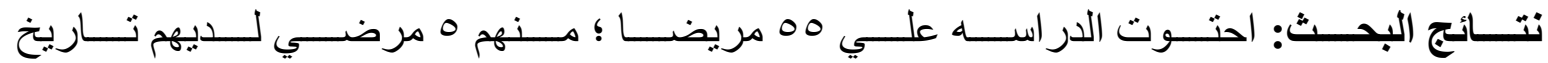

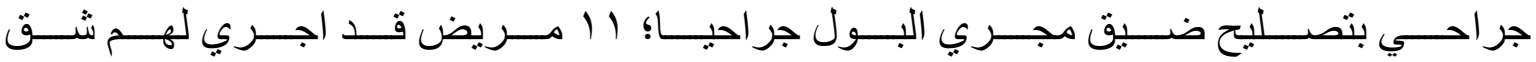




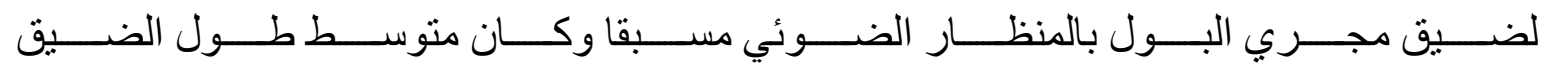

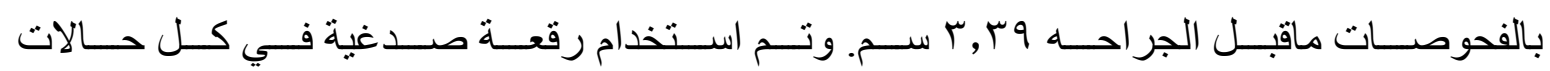

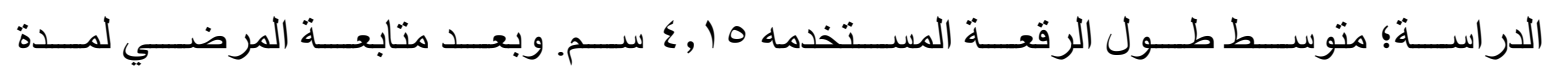

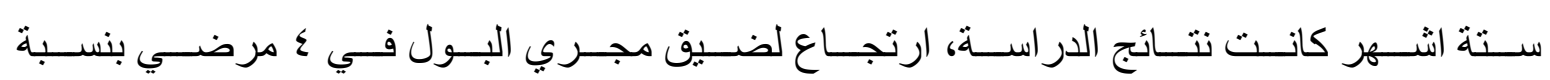

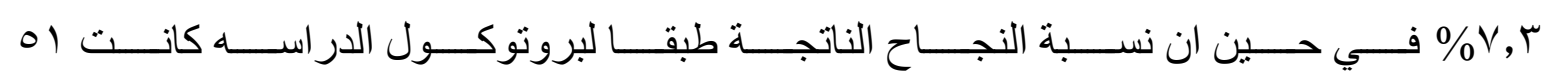

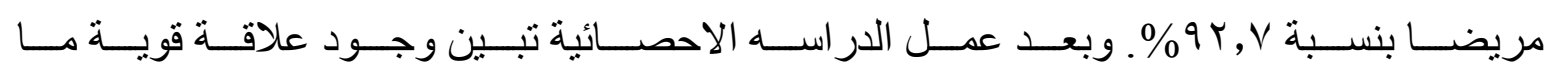

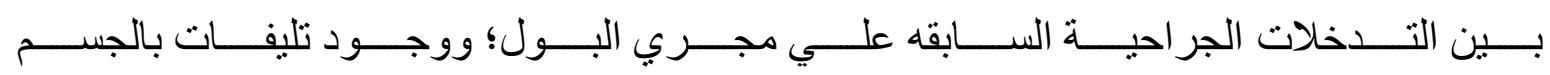
الاسفنجي المحيط لمجري البول

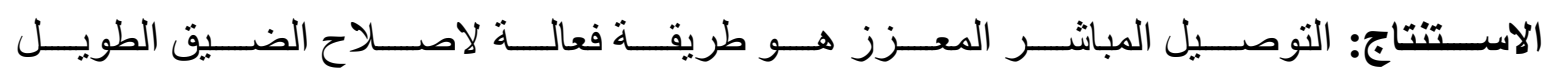

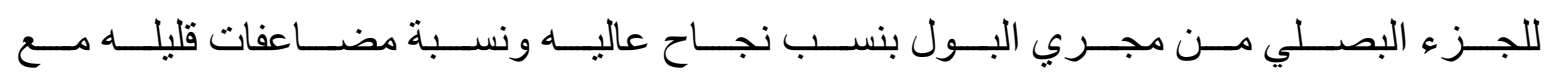
التوصية بمتابعة المرضي لفترة اطول. 